\title{
Analyst
}

Check for updates

Cite this: Analyst, 2020, 145, 3424

\section{Trace manganese detection via differential pulse cathodic stripping voltammetry using disposable electrodes: additively manufactured nanographite electrochemical sensing platforms $\dagger$}

\author{
Diego P. Rocha, (D) ${ }^{a, b}$ Christopher W. Foster, (D) ${ }^{a}$ Rodrigo A. A. Munoz, (D) ${ }^{b}$ \\ Gary A. Buller, ${ }^{a}$ Edmund M. Keefe ${ }^{a}$ and Craig E. Banks iD *a
}

\begin{abstract}
Additive manufacturing is a promising technology for the rapid and economical fabrication of portable electroanalytical devices. In this paper we seek to determine how our bespoke additive manufacturing feedstocks act as the basis of an electrochemical sensing platform towards the sensing of manganese(II) via differential pulse cathodic stripping voltammetry (DPCSV), despite the electrode comprising only $25 \mathrm{wt} \%$ nanographite and 75 wt\% plastic (polylactic acid). The Additive Manufactured electrodes (AM-electrodes) are also critically compared to graphite screen-printed macroelectrodes (SPEs) and both are explored in model and real tap-water samples. Using optimized DPCSV conditions at $\mathrm{pH}$ 6.0, the analytical outputs using the AM-electrodes are as follows: limit of detection, $1.6 \times 10^{-9} \mathrm{~mol} \mathrm{~L}^{-1}\left(0.09 \mu \mathrm{g} \mathrm{L}^{-1}\right)$; analytical sensi-

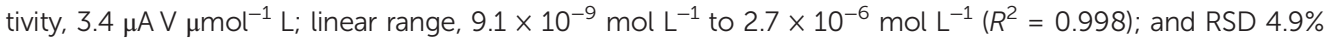
$\left(N=10\right.$ for $1 \mu \mathrm{mol} \mathrm{L} L^{-1}$ ). These results are compared to screen-printed macroelectrodes (SPEs) giving comparable results providing confidence that AM-electrodes can provide the basis for useful electrochemical sensing platforms. The proposed electroanalytical method (both AM-electrodes and SPEs) is shown to be successfully applied for the determination of manganese(॥) in tap water samples and in the analysis of a certified material (drinking water). The proposed method is feasible to be applied for in-loco analyses due to the portability of sensing; in addition, the use of AM-printed electrodes is attractive due to their low cost.
\end{abstract}

Received 4th January 2020, Accepted 9th March 2020

DOI: $10.1039 /$ d0an00018c

rsc.li/analyst
$\left.\mathrm{L}^{-1}\right) .{ }^{9,10}$ Therefore, strict monitoring of manganese at trace/low levels within water samples is very important.

Several techniques can be used for the determination of manganese such as atomic absorption spectrometry (AAS), inductively coupled plasma optical emission spectrometry (ICP-OES) and inductively coupled plasma mass spectrometry (ICP-MS). ${ }^{11}$ However, although these techniques present high sensitivity for manganese determination, they present drawbacks such as high cost, being highly specialized, need for preconcentration and/or separation and the non-feasibility of carrying out in-loco analyses. ${ }^{3,4,12,13}$ Alternatively, electroanalytical methodologies, such as stripping voltammetry, can be applied for the determination of trace levels of manganese due to the selective, sensitive, rapid and portable nature of the techniques. ${ }^{14}$ Anodic stripping voltammetry (ASV) can be applied for the determination of manganese(II) using mercury and bismuth-modified electrodes; ${ }^{6,15}$ this is based upon manganese deposition at the working electrode surface and subsequent anodic redissolution of the deposited manganese $\left(\mathrm{Mn}^{0}\right)$. However, this technique presents a disadvantage of requiring a large reduction potential $\left(E_{\mathrm{dep}}=-1.7 \mathrm{~V} v\right.$ s. SCE $)$ to electrochemically reduce $\mathrm{Mn}^{2+}$ to $\mathrm{Mn}^{0}$; this potential may lead 
to intermetallic compound formation ${ }^{16}$ limiting its analytical utility. To overcome this disadvantage, cathodic stripping voltammetry (CSV) with different working electrodes can be used. ${ }^{14,17}$ The technique is based on first applying a pre-concentration step, where the electrode potential is held sufficiently positive to form insoluble manganese(Iv) dioxide on the electrode surface. After a chosen pre-concentration time, the potential is then swept negative, producing a characteristic voltammetric stripping peak arising from the reduction of manganese(Iv) dioxide back to manganese(II). ${ }^{18}$ Due to the underlying electrochemical mechanism and the limited range of metal ions that can undergo such a reversible transformation, the approach of cathodic stripping voltammetry is very selective and suffers from limited interferents.

Electrochemical methods for manganese detection have been reported previously. ${ }^{2,3,6,12-14,18-26}$ For instance, Rusinek and colleagues ${ }^{2}$ developed a new sensor based on polymercoated indium tin oxide for manganese detection in natural water samples. Kang et $a l^{3}{ }^{3}$ utilized a copper-based electrochemical sensor with a palladium electrode to determine manganese in water samples. Banks and collaborators ${ }^{6}$ compared ASV and CSV for manganese detection in marine sediments and they concluded that CSV coupled with a borondoped diamond electrode (BDDE) provided better results. Saterlay and colleagues ${ }^{20}$ developed a sono-cathodic stripping voltammetry method using as a working electrode a BDDE for manganese determination in instant tea reaching a very low detection limit of $10^{-11} \mathrm{~mol} \mathrm{~L}^{-1}$ (2 min deposition). However, several procedures using modified electrodes ${ }^{3,18,22}$ and/or high-cost electrodes, such as palladium, ${ }^{3}$ platinum, ${ }^{22}$ and BDDE, ${ }^{6,20,25}$ present some drawbacks.

Screen-printed electrodes (SPEs) may currently be the most suitable electrochemical sensors for field analysis due to their low cost, high reproducibility and ability to mimic the electroanalytical performance of conventional solid electrodes, being feasible for field analysis in the biomedical, environmental and industrial areas. ${ }^{27,28}$ Another type of electrode that has gained prominence in recent years is additively manufactured (AM) electrodes. AM-electrodes can be fabricated quickly at very low costs, requiring only a 3D design (designed in specialized software), a 3D printer and polymer material cartridges, being possible to print modified conductive electrodes with other materials (nanotubes, graphene and metal particles) for different analyses. ${ }^{29-34}$

In this work, we report for the first time, the use of AM-electrodes as the basis of electrochemical sensing platforms for the trace determination of manganese(II) in water samples via differential pulse cathodic stripping voltammetry (DPCSV) and critically compare these to SPEs. Under optimized conditions, the analytical outputs obtained using the SPE are compared with those acquired at AM-printed electrodes, where the latter provided improvements over the former, despite the electrode being composed mostly of plastic ( $25 \mathrm{wt} \%$ nanographite and 75 wt $\%$ plastic PLA). Real samples were analysed and the manganese(II) concentrations found were below the detection limit; thus recovery tests were performed and acceptable values between 96 and 105\% were achieved. The electrochemical sensors were also verified to determine manganese (II) in a certified water sample. Both electrochemical sensors are shown to be able to determine manganese at trace levels (nmol $\mathrm{L}^{-1}$ region), with a wide linear range, with the additional benefit of low cost.

\section{Experimental section}

\section{Reagents, solutions and samples}

All chemicals used in this work were of analytical grade, therefore without the need for any treatment before use. Acetic acid $(99 \%$, $\mathrm{m} / \mathrm{v})$, phosphoric acid $(85 \%, \mathrm{~m} / \mathrm{v})$, boric acid $(99.5 \%, \mathrm{~m} / \mathrm{m})$ and sodium hydroxide $(98 \%, \mathrm{~m} / \mathrm{m})$ were purchased from SigmaAldrich (Gillingham, UK). Manganese(II) chloride tetrahydrate was obtained from Laboratory FSA Supplies (England). All solutions were prepared via dissolving or diluting the reagents in water or in a suitable supporting electrolyte, using water subjected to a reverse osmosis treatment system and finally purified in a Millipore Milli-Q system (resistivity $\geq 18.2 \mathrm{M} \Omega \mathrm{cm}$ ). The manganese stock solution $18.2 \mathrm{mmol} \mathrm{L}^{-1}\left(1000 \mu \mathrm{g} \mathrm{mL}^{-1}\right)$ was made by dissolving a determined mass of manganese(II) chloride tetrahydrate in high-purity deionized water and subsequent acidification with an ultra-trace amount of nitric acid. Tap water samples were collected using $50 \mathrm{~mL}$ plastic centrifuge tubes (Falcon) previously rinsed with high-purity deionized water. These samples were immediately analysed after collection with no further treatment and simply diluted (2-fold) in a supporting electrolyte. A standard reference material of Trace Metals in Drinking Water (Level 2, ALPHA APS-1075 (Lot\#918109), Stevensville, Michigan, USA), obtained from Alpha Resources (https://www.alpharesources.com/ index.php), was utilized to check the accuracy of manganese determination at both disposable electrodes. All experiments were performed at room temperature without oxygen removal.

\section{Instrumentation}

Electrochemical measurements utilised a PGSTAT 204 controlled by Nova 2.1 software (Metrohm Autolab B. V.; Ultrecht The Netherlands). A 728 Magnetic Stirrer purchased from Metrohm was used during the analyses (deposition step). $\mathrm{pH}$ measurements were performed before all experiments using a pH meter (Mettler Toledo, Switzerland).

\section{Electrodes and cells}

Graphite screen-printed macroelectrodes (SPEs) were made comprising a three-electrode configuration with a graphite working macroelectrode ( $3.1 \mathrm{~mm}$ diameter), a graphite counter electrode and a $\mathrm{Ag} / \mathrm{AgCl}$ pseudo-reference electrode. ${ }^{35}$ The SPEs were manufactured at MMU and have been previously characterized. ${ }^{36,37}$ An "edge connector" was used to accommodate the SPEs and electrically connects them to the potentiostat as previously reported. ${ }^{38,39}$ Measurements using the SPEs were carried out using a glass cell with an internal volume of $10 \mathrm{~mL}$. 


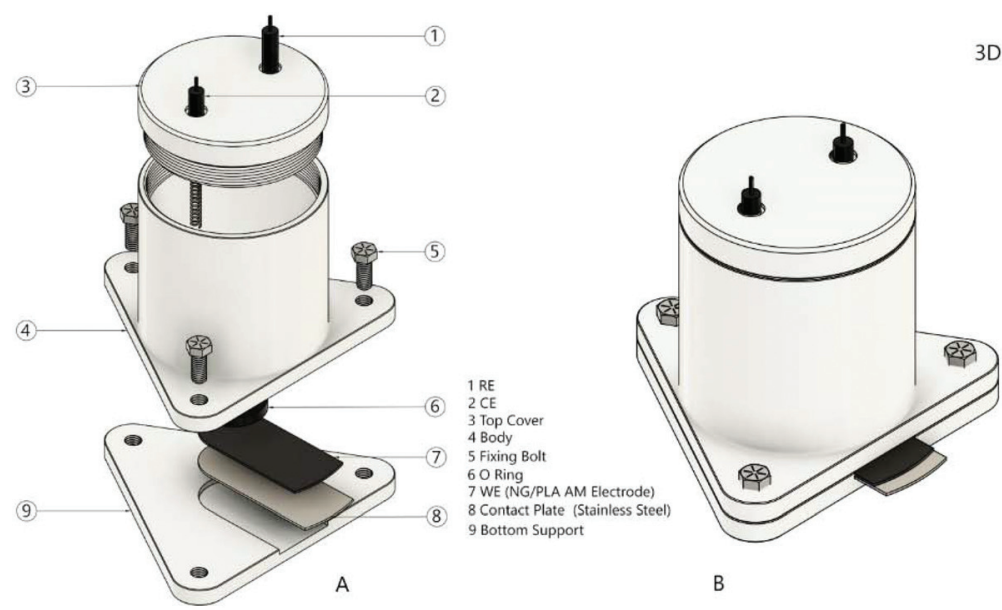

3D Printed cell and electrodes

Fig. 1 Schematic diagram of the 3D-printed cell to utilise the AM-electrodes. (A) 3D-printed cell parts; (B) complete 3D-printed cell; (C) transversal cut vista of the 3D-printed cell. CE, RE and WE were counter electrode (platinum wire), reference electrode $(\mathrm{Ag} / \mathrm{AgCl}(3 \mathrm{~mol} \mathrm{~L}-1 \mathrm{KCl}))$ and working electrode (AM-electrodes), respectively.

The AM-electrodes were prepared from the fabricated bespoke feedstocks (filaments) comprising nanographite (NG) and polylactic acid (PLA). This was achieved via the pre-mixing of NG (Sigma Aldrich, UK) and PLA. For this, $3.75 \mathrm{~g}$ of mesoporous NG were dispersed within excess xylene by sonication for 10 minutes. Thereafter, the resulting mixture was heated (under reflux) at $160{ }^{\circ} \mathrm{C}$ for 3 hours in a silicon oil bath, $11.25 \mathrm{~g}$ of PLA were then added to the mixture and maintained for another 3 hours. After this, the resulting mixture was then recrystallized using excess methanol, vacuum filtered and dried overnight to evaporate the remaining xylene. In order to obtain the filament, the resulting NG/PLA material was placed within a MiniCTW twin-screw extruder (Thermo Scientific) and heated at $200{ }^{\circ} \mathrm{C}$ with a screw speed of $30 \mathrm{rpm}$. The resulting filament was AM (3D printed) using a ZMorph ${ }^{\circledR}$ printer (Wroclaw - Poland) with a direct drive extruder at $190{ }^{\circ} \mathrm{C}$. The AM-electrodes were cut using scissors with the following dimensions: $34 \mathrm{~mm} \times 12 \mathrm{~mm}$. Prior to electrochemical measurements, the AM-electrodes were polished with wet sandpaper. When the AM-electrode was used, counter and reference electrodes were, respectively, a platinum wire and $\mathrm{Ag} /$ $\mathrm{AgCl}\left(3 \mathrm{~mol} \mathrm{~L}^{-1} \mathrm{KCl}\right)$. Measurements were carried out using a 3D-printed cell with an internal volume of $5 \mathrm{~mL}$ (Fig. 1). The design of this cell was based on previously developed templates described in the literature; ${ }^{40}$ an O-ring defines the electrochemical working area (geometric area: $0.22 \mathrm{~cm}^{2}$ ). Note that this is the limit ( $25 \%$ conductive material) that can be successfully fabricated and can be reliability printed (additively manufactured).

\section{Results and discussion}

The response of the Additively Manufactured electrodes (AMelectrodes) for manganese(II) detection under stirred conditions was explored first using differential pulse cathodic stripping voltammetry (DPCSV). The technique is based on first applying a pre-concentration step, where the electrode potential is held sufficiently positive to form insoluble manganese(Iv) dioxide upon the AM-electrode surface: $\mathrm{Mn}^{+2}+2 \mathrm{H}_{2} \mathrm{O}$ $\rightarrow \mathrm{MnO}_{2}+4 \mathrm{H}^{+}+2 \mathrm{e}^{-}$. Following a chosen pre-concentration time, the potential is then swept negative, producing a characteristic voltammetric stripping peak arising from the electrochemical reduction of manganese(rv) dioxide back to manganese(II) which serves as the (electro)analytical signal. The effect of $\mathrm{pH}$ ( 2 to 9) upon the magnitude of the electrochemical signal was first explored using a fixed manganese concentration of $1.8 \times 10^{-3} \mathrm{~mol} \mathrm{~L}^{-1}$. A plot of the cathodic peak current (analytical signal) vs. $\mathrm{pH}$ was constructed where the signal was found to increase with $\mathrm{pH}$, with maxima observed at $\mathrm{pH} 6$ after which, with increasing the $\mathrm{pH}$ from 7 to 9 , the magnitude of the electroanalytical signal was observed to decrease. At $\mathrm{pH}$ values lower than 4 , there is a tendency of incomplete deposition of insoluble $\mathrm{MnO}_{2}$ at the working electrode surface, while at $\mathrm{pH}$ values higher than 9 (basic media) the manganese is not sufficiently soluble and can precipitate as $\mathrm{Mn}(\mathrm{OH})_{2}$. In order to obtain optimal electroanalytical performances, various parameters affecting cathodic stripping voltammetry were explored, namely the deposition potential, time and stirring rate. Each parameter was diligently explored and the optimal parameters were deduced (Fig. ESI $1-3 \dagger$ ) and are reported in ESI Table 1. $\dagger$

Next the response of the AM-electrodes towards the sensing of manganese(II) was explored. Using DPCSV, aliquots of manganese(II) were made into a $\mathrm{pH} 6 \mathrm{BR}$ buffer with the analytical signal monitored as a function of concentration as shown in Fig. 2. A wider linear range between $9.10 \times 10^{-9} \mathrm{~mol}$ $\mathrm{L}^{-1}$ and $2.70 \times 10^{-6} \mathrm{~mol} \mathrm{~L}^{-1}$ using a 350 seconds deposition time was found to be achievable, with an excellent coefficient of determination $\left(R^{2}\right)$ of 0.998. A linear dependence of the stripping signal (peak area $(\mathrm{Y}, \mu \mathrm{A} \mathrm{V}))$ versus manganese concentration $\left(\left[\mathrm{Mn}^{2+}\right], \mu \mathrm{mol} \mathrm{L}^{-1}\right)$ can be described by the equation 


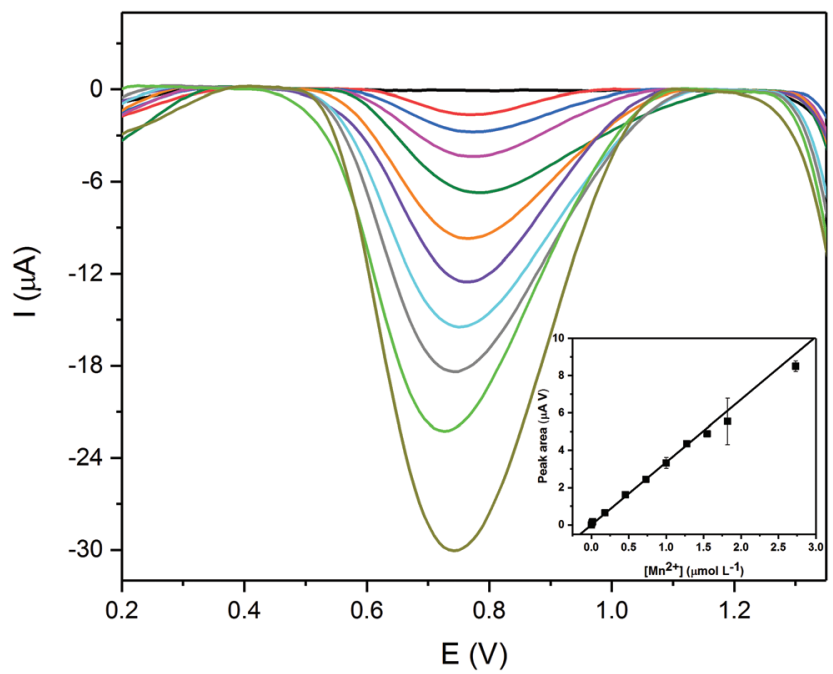

Fig. 2 Background-corrected DPCSV from increasing concentrations of manganese(II) using AM-electrodes: blank (black line); red line $(9.10 \times$ $\left.10^{-9} \mathrm{~mol} \mathrm{~L}^{-1} / 0.5 \mu \mathrm{g} \mathrm{L}^{-1}\right)$; blue line $\left(1.82 \times 10^{-8} \mathrm{~mol} \mathrm{~L}^{-1} / 1.0 \mu \mathrm{g} \mathrm{L}^{-1}\right)$; pink line $\left(1.82 \times 10^{-7} \mathrm{~mol} \mathrm{~L}^{-1} / 10.0 \mu \mathrm{g} \mathrm{L}^{-1}\right)$; dark green line $\left(4.55 \times 10^{-7} \mathrm{~mol}\right.$ $\left.\mathrm{L}^{-1} / 25.0 \mu \mathrm{g} \mathrm{L}^{-1}\right)$; orange line $\left(7.30 \times 10^{-7} \mathrm{~mol} \mathrm{~L}^{-1} / 40.0 \mu \mathrm{g} \mathrm{L}^{-1}\right)$; purple line $\left(1.00 \times 10^{-6} \mathrm{~mol} \mathrm{~L}^{-1} / 55.0 \mathrm{mg} \mathrm{L}^{-1}\right)$; cyan line $\left(1.30 \times 10^{-6} \mathrm{~mol} \mathrm{~L}^{-1} /\right.$ $\left.70.0 \mu \mathrm{g} \mathrm{L}^{-1}\right)$; grey line $\left(1.50 \times 10^{-6} \mathrm{~mol} \mathrm{~L}^{-1} / 85.0 \mu \mathrm{g} \mathrm{L}^{-1}\right)$; green line $\left(1.80 \times 10^{-6} \mathrm{~mol} \mathrm{~L}^{-1} / 100.0 \mu \mathrm{g} \mathrm{L}^{-1}\right)$; dark yellow line $\left(2.70 \times 10^{-6} \mathrm{~mol} \mathrm{~L}^{-1} /\right.$ $150.0 \mu \mathrm{g} \mathrm{L}^{-1}$ ). The inset is a plot of peak area versus manganese(॥) concentrations. CSDPV conditions: deposition potential: $+1.05 \mathrm{~V}$; time deposition: $350 \mathrm{~s}$; scan from +1.4 to $-0.4 \mathrm{~V}$; stirring rate: $1500 \mathrm{rpm}$; interval time $=0.1 \mathrm{~s}$, step potential $=8 \mathrm{mV}$; modulation amplitude $=$ $250 \mathrm{mV}$, modulation time $=0.02 \mathrm{~s}$ and standby potential $=$ 0.0 V. Supporting electrolyte: BR buffer $(\mathrm{pH} \mathrm{6.0)}$.

$Y=0.0014 \pm 0.0001+3.42 \pm 0.07\left[\mathrm{Mn}^{2+}\right]$. The detection limit (99.7\% confidence level) and the $\operatorname{RSD}\left(N=10\right.$ for $\left.1 \mu \mathrm{mol} \mathrm{L}{ }^{-1}\right)$ (Fig. ESI- $4 \dagger$ ) were found to be $1.6 \times 10^{-9} \mathrm{~mol} \mathrm{~L}^{-1}$ and $4.9 \%$, respectively. The proposed AM-electrode electroanalytical sensing platform shows excellent analytical features, a wide linear range and a low detection limit with potential for "in the field" manganese(II) determination in real samples at trace levels.

For comparative purposes, manganese(II) determination was also performed using SPEs. Using the same experimental conditions reported above for the AM-electrodes, the analytical performance towards the sensing of manganese(II) was explored with the analytical signal monitored as a function of concentration. The resulting DPCSV curves can be observed in Fig. ESI-5 $\dagger$ where a linear concentration range of peak area versus concentration from $9.10 \times 10^{-9} \mathrm{~mol} \mathrm{~L}^{-1}$ to $1.82 \times 10^{-6}$ mol L ${ }^{-1}$ is achievable with an excellent coefficient of determination $\left(R^{2}\right)$ of 0.996 observed. The relationship between the peak area $(\mathrm{Y}, \mu \mathrm{A} \mathrm{V})$ and manganese concentration $\left(\left[\mathrm{Mn}^{2+}\right]\right.$, $\left.\mu \mathrm{mol} \mathrm{L}{ }^{-1}\right)$ can be described by the equation $Y=0.032 \pm 0.002+$ $2.51 \pm 0.09\left[\mathrm{Mn}^{2+}\right]$. The relative standard deviation (RSD) value was estimated to be $6.74 \%$ for ten consecutive measurements

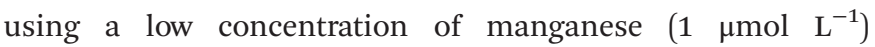
(Fig. ESI-6 $\dagger$ ). The detection limit of $2.4 \times 10^{-9} \mathrm{~mol} \mathrm{~L}^{-1}(99.7 \%$ confidence level) was calculated as follows: $3 s B / S$, in which $s B$
Table 1 Analytical features of the proposed method for manganese determination at the AM-electrodes and SPEs

\begin{tabular}{lll}
\hline Analytical feature & AM-electrodes & SPEs \\
\hline Linear range $\left(\mathrm{mol} \mathrm{L}^{-1}\right)$ & $9.10 \times 10^{-9}$ to & $9.10 \times 10^{-9}$ to \\
$R^{2}$ & $2.70 \times 10^{-6}$ & $1.82 \times 10^{-6}$ \\
Sensitivity $\left(\mu \mathrm{A} \mathrm{V} \mu \mathrm{mol}^{-1} \mathrm{~L}\right)$ & 0.998 & 0.996 \\
$\mathrm{RSD}\left(N=10\right.$ for $\left.1 \mu \mathrm{mol} \mathrm{L}^{-1}\right)$ & 3.4 & 2.5 \\
Detection limit $\left(\mathrm{mol} \mathrm{L}^{-1}\right)$ & $1.9 \%$ & $6.7 \%$ \\
& & $2.4 \times 10^{-9}$
\end{tabular}

and $S$ were the standard deviation for ten consecutive measurements of baseline noise and the slope of the analytical curve, respectively.

The (electro)analytical performances of the AM-electrodes and SPEs are summarised within Table 1. The use of AMelectrodes shows an improvement in the analytical characteristics, with $36 \%$ increase in sensitivity obtained. A decrease of $33 \%$ in the detection limit is also achieved. In addition, a larger linear range and a smaller RSD were obtained compared to the SPE results. However, if one normalises the sensitivity with the geometric electrode area, the sensitivities are 15.5 and 35.7 $\mu \mathrm{A} \mathrm{V} \mu \mathrm{mol}^{-1} \mathrm{~L} \mathrm{~cm}^{-2}$ for the AM-electrodes and SPEs, respectively. That said, both are completely different electrochemical sensing platforms with the AM-electrodes comprised of $75 \%$ plastic! Note that this is the limit that can be successfully fabricated and can be reliability printed (additively manufactured); thus the limit in this case (PLA) is $25 \%$ conductive material.

We next turn to exploring the AM-electrodes and SPEs for the sensing of manganese(II) in three samples of tap water. The water samples were 2-fold diluted in the supporting electrolyte. Using the proposed protocol described above and optimized conditions, similar results were obtained for both sensors. Since manganese(II) signals were not achieved in all samples as the concentration found was below the detection limit, the samples were fortified with a very low manganese(II) concentration $\left(3.6 \times 10^{-7} \mathrm{~mol} \mathrm{~L}^{-1}\right.$, final concentration in the cell after the sample is 2-fold diluted). Satisfactory recovery values between $96 \%$ and 105\% were acquired, showing acceptable accuracy of the developed method considering the low manganese concentration adopted for the experiment. Standard addition curves showed good linearity $\left(R^{2}>0.99\right)$ and the results are shown in Fig. 3. In addition, the accuracy of the proposed protocol was evaluated by the analysis of ALPHA APS 1075 (Trace Metals in Drinking Water) certified material again measurements made via the standard addition methodology. The type and concentration of the trace metals (including manganese) present in this certified material are shown in ESI Table $2 . \dagger$ A statistically significant difference was not observed between the AM-electrodes, $7.10( \pm 0.25) \times 10^{-4} \mathrm{~mol} \mathrm{~L}^{-1}$ and SPEs $7.20( \pm 0.25) \times 10^{-4} \mathrm{~mol} \mathrm{~L}^{-1}$ comparing well with the certified material value of $\left(7.28 \times 10^{-4} \mathrm{~mol} \mathrm{~L}^{-1}\right)$ at a confidence level of $95 \%$. As can be seen in ESI Table $2 \dagger$ many other metal ions are present in the ALPHA APS 1075 in very high concentration and despite that, no interference problems were observed in the 

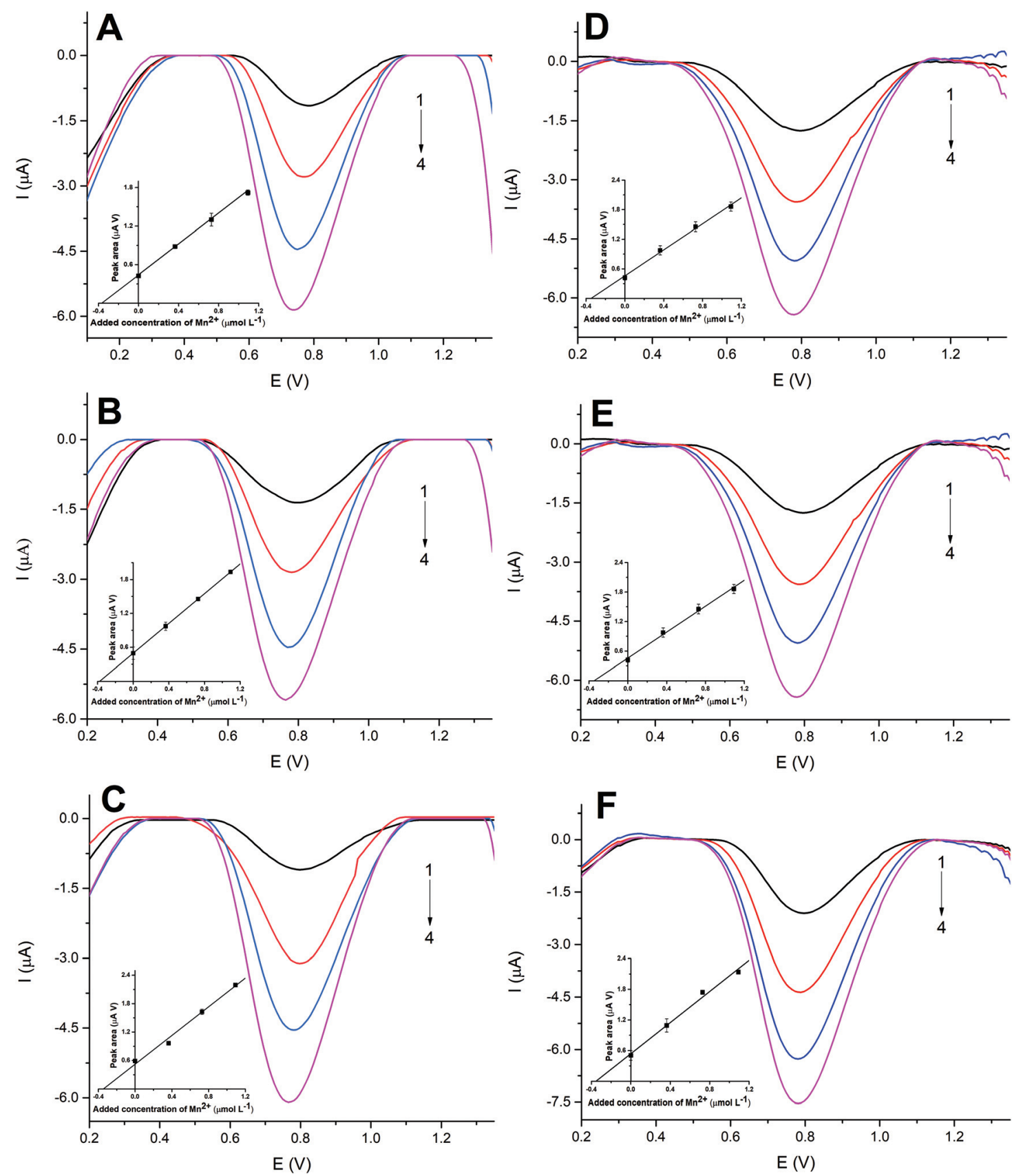

Fig. 3 Background-corrected DPCSV for manganese(॥) determination in three different tap water samples spiked with $3.6 \times 10^{-7}$ mol $\mathrm{L}^{-1}$ and three additions of manganese standards from $3.6 \times 10^{-7} \mathrm{~mol} \mathrm{~L}^{-1}$ to $1.08 \times 10^{-6} \mathrm{~mol} \mathrm{~L}^{-1}$ onto SPEs (left: (A), (B) and (C)) and onto AM-electrodes (right: (D), $(\mathrm{E})$ and $(\mathrm{F}))$. The insets are the respective analytical curves. DPCSV conditions: deposition potential: $+1.05 \mathrm{~V}$; time deposition: $350 \mathrm{~s}$; scan from $+1.4 \mathrm{~V}$ to $-0.4 \mathrm{~V}$; stirring rate: $1500 \mathrm{rpm}$; interval time $=0.1 \mathrm{~s}$, step potential $=8 \mathrm{mV}$; modulation amplitude $=250 \mathrm{mV}$, modulation time $=0.02 \mathrm{~s}$ and standby potential $=0.0 \mathrm{~V}$. Supporting electrolyte: BR buffer $(\mathrm{pH} 6.0)$.

analysis. Additionally, we must emphasize that due to the high deposition potential of $\mathrm{MnO}_{2}$ and subsequent voltammetric scanning of positive to negative potentials, the interference caused by several metal ions is largely eliminated ${ }^{3}$ and the use of cathodic stripping voltammetry is highly selective for the manganese determination. Thus, we have demonstrated that the AM-electrodes and SPEs can be successfully applied for the trace determination of manganese(II) in tap water samples.

\section{Conclusions}

We have demonstrated that the AM-electrodes can be successfully used for the sensing of manganese(II) determination at trace levels via DPCSV in tap water samples. The analytical performance of the AM-electrodes and SPEs is benchmarked within Table 2 demonstrating comparable responses to previous literature reports. As can be observed, the proposed pro- 
Table 2 Literature overview for the electroanalytical sensing of manganese in a range of electrochemical platforms using cathodic stripping voltammetry

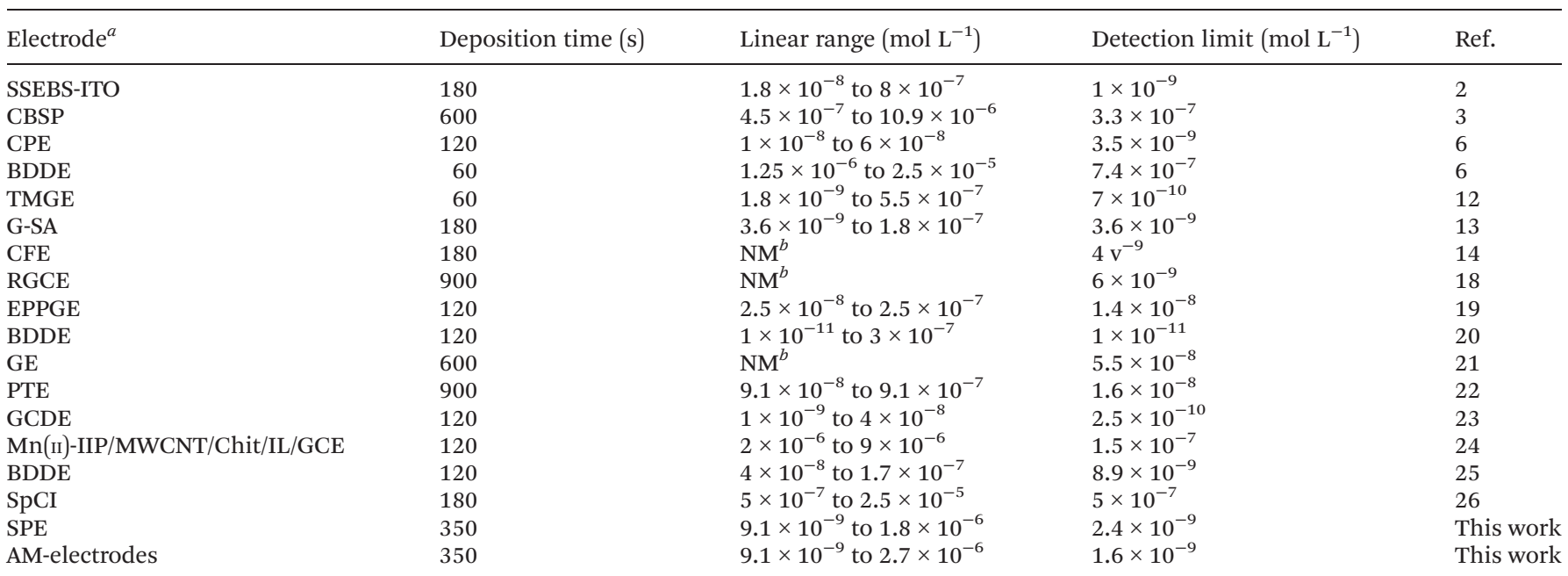

${ }^{a}$ TMGE - thick-film graphite-containing electrode modified with formazan; CBSP - copper-based electrochemical sensor with a palladium electrode; SSEBS-ITO - polystyrene-block-poly(ethylene-ran-butylene)-block-polystyrene-sulfonate coated indium tin oxide; G-SA - graphite/styreneacrylonitrile copolymer composite electrodes composite electrodes; CFE - carbon film electrodes fabricated from carbon resistors of $2 \Omega$; GE graphite electrode; RGCE - rotating glassy carbon disk electrode; PTE - micro fabricated platinum thin-film electrode; EPPGE - edge plane pyrolytic graphite electrodes; SpCI - stencil-printed carbon ink electrodes; BDDE - boron-doped diamond electrode; Mn(II)-IIP/MWCNT/Chit/IL/GCE glassy carbon electrode modified with a multi-walled carbon nanotube-chitosan-ionic liquid nanocomposite decorated with an ion imprinted polymer; GCDE - glassy carbon disk electrode; CPE-carbon paste electrode; SPE - graphite screen-printed electrode; NG/PLA AM-electrode - nano graphite (NG)/PLA. ${ }^{b}$ NM - Not mentioned.

tocol shows similar or better performance when compared with previously published works in terms of linear range and detection limit. The detection limit is dependent on the deposition time; thus, it can be observed that methods reported in Table 2 use differing times; hence direct comparisons are not strictly achievable. Also, some of the electrodes reported in Table 2 are expensive and prohibit adoption for the sensing of manganese(II). Therefore, the method developed here, based on our knowledge, presents for the first time the possibility of the use of disposable and low cost electrodes in the manganese(II) determination in water samples. Finally, it is important to remember that the AM-electrodes are composed of $25 \mathrm{wt} \%$ nanographite and $75 \mathrm{wt} \%$ plastic and yet still provide analytical useful outputs. The ability to use AM for the rapid fabrication of low cost sensors is clearly achievable.

\section{Conflicts of interest}

There are no conflicts to declare.

\section{Acknowledgements}

Funding from the Engineering and Physical Science Research Council (Reference: EP/N001877/1) and a British Council Institutional Grant Link (No. 172726574) is acknowledged. The Brazilian agency CAPES is also acknowledged (001 and Pro-Forense 23038.007073/2014-12).

\section{References}

1 World Health organization, Air Quality Guidelines for Europe, WHO regional publications, Copenhagen, 2nd edn, 2001, pp. 1-13.

2 C. A. Rusinek, A. Bange, M. Warren, W. Kang, K. Nahan, I. Papautsky and W. R. Heineman, Anal. Chem., 2016, 88, 4221.

3 W. Kang, X. Pei, A. Bange, E. N. Haynes, W. R. Heineman and I. Papautsky, Anal. Chem., 2014, 86, 12070.

4 P. Phansi, C. Henr, E. Palacio and P. Wilairat, Anal. Methods, 2014, 6, 5088.

5 R. Witholt, R. H. Gwiazda and D. R. Smith, Neurotoxicol. Teratol., 2000, 22, 851.

6 C. E. Banks, J. Kruusma, R. R. Moore, P. Tom, J. Davis and R. G. Compton, Talanta, 2005, 65, 423.

7 W. Yue, A. Bange, B. L. Riehl, B. D. Riehl, J. M. Johnson, I. Papautsky and R. Heineman, Electroanalysis, 2012, 24, 1909.

8 R. A. Yokel, Manganese Flux Across the Blood-Brain Barrier, NeuroMol. Med., 2009, 11, 297-310.

9 D. A. Otto and H. K. Hudnell, Environmental manganese: guideline exposure levels, evidence of health effects and research needs, (n.d.). https://cfpub.epa.gov/si/si_public record_Report.cfm?Lab=NHEERL\&dirEntryID=76758 (accessed March 5, 2019).

10 M. P. Colombini and R. Fuoco, Talanta, 1983, 30, 901.

11 A. X. S. Qian, G. H. F. He and X. Han, Analyst, 2001, 126, 239. 
12 N. Y. Stozhko, O. V. Inzhevatova, L. I. Kolyadina and G. N. Lipunova, J. Anal. Chem., 2005, 60, 163.

13 J. Jin, F. Xu and T. Miwa, Electroanalysis, 2000, 12, 610.

14 O. M. S. Filipe and C. M. A. Brett, Talanta, 2003, 61, 643.

15 C. M. A. Brett and M. M. P. M. Neto, J. Electroanal. Chem. Interfacial Electrochem., 1989, 258, 345.

16 J. Di and F. Zhang, Talanta, 2003, 60, 31.

17 H. S. El-desoky and I. M. Ismail, J. Solid State Electrochem., 2013, 17, 3153.

18 J. S. Roitz and K. W. Bruland, Anal. Chim. Acta, 1997, 344, 175.

19 C. M. Welch, C. E. Banks, S. Komorsky-Lovric and R. G. Compton, Croat. Chem. Acta, 2006, 79, 27.

20 A. J. Saterlay, J. S. Foord and R. G. Compton, Analyst, 1999, 24, 1791.

21 J. Labuda, M. Vaníčková and E. Beinrohr, Mikrochim. Acta, 1989, 97, 113.

22 W. Kang, C. Rusinek, A. Bange, E. Haynes, W. R. Heineman and I. Papautsky, Determination of Manganese by Cathodic Stripping Voltammetry on a Microfabricated Platinum Thin - film Electrode, Electroanalysis, 2017, 29, 686-695.

23 J. J. In, X. U. Fan and T. M. Iwa, Square-Wave Cathodic Stripping Voltammetry of Ultratrace Manganese in the Presence of Ultrasound Irradiation, Anal. Sci., 2000, 16, 317-319.

24 M. Roushani, Z. Saedi, F. Hamdi and B. Z. Dizajdizi, J. Electroanal. Chem., 2017, 804, 1.

25 A. Goodwin, A. L. Lawrence, C. E. Banks, F. Wantz, D. Omanovi, S. Komorsky-Lovrić and R. G. Compton, Anal. Chim. Acta, 2005, 533, 141.

26 K. E. Berg, J. A. Adkins, S. E. Boyle and C. S. Henry, Electroanalysis, 2016, 28, 679, DOI: 10.1002/ elan.201500474.

27 M. Li, Y.-T. Li, D.-W. Li and Y.-T. Long, Anal. Chim. Acta, 2012, 734, 31.
28 J. P. Hart and S. A. Wring, TrAC, Trends Anal. Chem., 1997, 16, 89.

29 A. Ambrosi and M. Pumera, Chem. Soc. Rev., 2016, 45, 2740 .

30 H. Bikas, P. Stavropoulos and G. Chryssolouris, Int. J. Adv. Manuf. Technol., 2016, 83, 389.

31 A. Ambrosi, J. G. S. Moo and M. Pumera, Adv. Funct. Mater., 2016, 26, 698.

32 E. M. Richter, D. P. Rocha, R. M. Cardoso, E. M. Keefe, C. W. Foster, R. A. A. Munoz and C. E. Banks, Anal. Chem., 2019, 91, 12844.

33 C. W. Foster, H. M. Elbardisy, M. P. Down, E. M. Keefe, G. C. Smith and C. E. Banks, Chem. Eng. J., 2020, 381, 122343.

34 V. Katic, P. L. dos Santos, M. F. dos Santos, B. M. Pires, H. C. Loureiro, A. P. Lima, J. C. M. Queiroz, R. Lander, R. A. A. Munoz and J. A. Bonacin, ACS Appl. Mater. Interfaces, 2019, 11, 38.

35 C. W. Foster, J. P. Metters, D. K. Kampouris and C. E. Banks, Ultraflexible Screen-Printed Graphitic Electroanalytical Sensing Platforms, Electroanalysis, 2014, 26, 262.

36 E. Blanco, C. W. Foster, L. R. Cumba, D. R. do Carmo and C. E. Banks, Analyst, 2016, 141, 2783.

37 L. R. Cumba, C. W. Foster, D. A. C. Brownson, J. P. Smith, J. Iniesta, B. Thakur, D. R. do Carmo and C. E. Banks, Analyst, 2016, 141, 2791.

38 F. E. Galdino, C. W. Foster, J. A. Bonacin and C. E. Banks, Anal. Methods, 2015, 7, 1208.

39 A. P. Ruas de Souza, C. W. Foster, A. V. Kolliopoulos, M. Bertotti and C. E. Banks, Analyst, 2015, 140, 4130.

40 R. M. Cardoso, D. M. H. Mendonça, W. P. Silva, M. N. T. Silva, E. Nossol, R. A. B. da Silva, E. M. Richter and R. A. A. Muñoz, Anal. Chim. Acta, 2018, 1033, 49. 